\title{
Kaupapa Māori evaluation: A collaborative journey
}

\section{Teah Carlson, Helen Moewaka Barnes and Tim McCreanor}

The interpretation and practice of kaupapa Māori evaluation (KME) take many forms, each involving its own set of considerations, challenges and outcomes. This article explores the complexities involved in a collaborative journey through an evaluation project where KME was a guiding principle, highlighting its successes and challenges. The evaluation aimed to benefit Ngāti Porou Hauora, a Māori health provider, and the community it served, by evaluating the effectiveness (as defined by the community) of a health literacy intervention. Ultimately, KME in this project was about meeting the aspirations of co-ownership, mutually beneficial outcomes and shared power by prioritising the participants' voices to shape and develop the criteria to determine the effectiveness of the intervention. Stakeholders' understanding of health literacy and the intervention varied, making the vision of collaboration more complex as individuals worked through personal, community and organisational implications. 


\section{Introduction}

Māori (the Indigenous peoples of Aotearoa New Zealand) have had negative experiences as subjects of research, which has often served to advance colonial powers (Bishop, 1999; Cochran et al., 2008; L. T. Smith, 2012). In more recent years there has been a shift to Māori re-purposing research, with kaupapa Māori an influential part of turning the tables on academic research methods and practices (Cram, 2016; Kerr, Penney, Moewaka Barnes, \& McCreanor, 2010; MastersAwatere, 2015). This shift has allowed Māori issues, concerns, ways of understanding, and practice to be placed at the centre of research enterprise rather than on the fringes. Principles and practices developed by Māori, such as those of kaupapa Māori evaluation (KME), can be applied effectively from the beginning of a research journey.

Descriptions of kaupapa Māori research range from broad guiding principles to more prescriptive notions. Taking the commonly agreed broad principles as a framework, the evaluation concerned itself with being led by Māori, collectivity, and transformation (Kerr, 2011; Moewaka Barnes, 2006). In applying these principles, the evaluation set out to develop approaches based on connections, partnerships and collaborations. However, discrepancies can emerge between expectations and practice as researchers and research 'partners' grapple with real-life contexts. This article explores the complexities involved in a collaborative journey through an evaluation project where KME was a guiding principle, highlighting its successes as well as some considerable challenges.

My (Teah Carlson's) research involved the conduct of a KME established on mutually beneficial foundations, where the goal was for Māori stakeholder groups to become co-designers and researchers, from the inception of the research through to the end. The evaluation aimed to benefit Ngāti Porou Hauora (NPH), a Māori health 
provider, and the community it served by evaluating the effectiveness-based on perceptions, practices, and experiences (as defined by the community) — of a health literacy intervention in their catchment. Within the intervention, health literacy was defined as "the ability to access, understand and act on information for health" (Nutbeam, 2008, p. 2076). The intervention was part of a larger international collaborative research project on cardiovascular disease (CVD) medication health literacy interventions, the New Zealand component of which involved one rural and one urban Māori health provider organisation. Both providers were involved from the outset with co-designing the larger project, both as active partners and as part of the research team. In addition, NPH (the rural organisation) was invited to be a part of a KME process that would evaluate the intervention with NPH participants and provide a framework that $\mathrm{NPH}$ could utilise for other health literacy interventions.

As a descendant of Ngāti Porou I had direct connections to the project and wanted to contribute to the positive development of my iwi (nation) by utilising research in a way that had real-life, community-based meaning and outcomes. I wanted the research to be an evolutionary process, where learning and changes were made along the way by all parties, me included. I envisaged the research would allow me to engage in a collaborative process and gain experience in this area. Finally, as part of my doctoral study I needed the research to address my own doctoral research questions and enable me to complete a thesis. I was supported in this by my supervisors, the co-authors of this article.

As an iwi member I was both an insider and positioned outside the community (L. T. Smith 1999). I am an insider as I am of Ngāti Porou descent, and the majority of my whānau (family) still reside in the rohe (iwi territory) and are current users and/or employees of $\mathrm{NPH}$ services. I am also positioned as an outsider because I attend 
university away from home, and no longer live in the takiwā (home area), and I have received a Western education. However, my connections and responsibilities will always remain with my iwi.

\section{Kaupapa Māori}

Kaupapa Māori originated out of concern for the unjust and harmful impacts endured by Māori at the hands of non-Māori researchers (Eketone, 2008; G. H. Smith, 1997; L. T. Smith, 1999; Walker, 1996). Kaupapa Māori theory (G. H. Smith, 1997) is the foundational lens for kaupapa Māori research and KME. KME is an evaluative method that seeks to explain, measure, and assess the quality of an intervention on the basis of how it relates to Māori and obligations that need to be considered under Te Tiriti o Waitangi ${ }^{1}$ (Moewaka Barnes, 2003). Kaupapa Māori theory, research, action and evaluation are critically oriented, methodologically eclectic, and encourage rigour while celebrating diversity, community-centred approaches and the expanding sense of understanding of the realms of te ao Māori (the Māori world). Kaupapa Māori research describes the everyday, taken-for-granted practices and knowledge of te ao Māori (Moewaka Barnes, 2000). As an approach, it places emphasis on the collective voice on the basis that we are all subjective beings enmeshed in our perceptions of reality. Kaupapa Māori research has played an integral role in reorienting social science research practices by creating a space for Māori to honour our histories, world views and knowledge. However, we still recognise the continued impact of the colonial discourse (L. T. Smith, 2012), including a rationalising impetus from science that sidelines these approaches and too often justifies a status quo of Māori marginalisation and disparities.

1 Te Tiriti o Waitangi: signed in 1840, the Treaty of Waitangi is an agreement between the British Crown and the Mãori peoples of Aotearoa. The Treaty essentially characterises a relationship between the Crown and iwi Māori which, through a mutually beneficial partnership, intended to ensure the wellbeing of all people in Aotearoa. 
In terms of practice, kaupapa Māori research can align closely with the principles of action research (AR) (Kerr et al., 2010). Both approaches emphasise community voice, collective understanding of issues, and developing participant definitions, processes, actions and outcomes. As a result, they both draw attention to areas of strategic importance by revealing real and pressing issues for the communities and participants concerned. AR also complements kaupapa Māori research because it includes a reflective cycle that ensures the research approach, processes and outcomes are not a fixed or static modality, but rather are flexible and adaptive (Kerr et al., 2010).

Notions of collaboration are used widely in descriptions of kaupapa Màori research, and by definition they are context specific. Collaborative approaches are grounded in the recognition of an interconnectedness and commonality of experiences as Māori, whānau, hapū (sub-nation) and iwi members, health consumers and health workers. Collaboration is about the collective process of theorising participation and co-designing opportunities for the involvement of iwi representatives, community members, and managerial, clinical and community staff in all stages of the research (design, data gathering, analysis and interpretation, dissemination). Examples of collaborative approaches that facilitate and underpin a collective process include "whitiwhiti kōrero" (reflexive/spiral dialogue) (Holmes 1992, cited in Bishop, 1996, p. 104), "co-exploration" (Diller 1993, cited in Noddings, 1995, p. 93), "collaborative storying" (Connelly \& Clandinin, 1990, p. 336), and "spiral discourse" (Bishop \& Glynn, 1999, p. 119).

Collaboration goes beyond notions of being responsive to Māori and conducting research in a culturally appropriate way, towards a more reciprocal, mutually invested and beneficial approach (Cram, 2015). Durie 2005 (cited in Ahuriri-Driscoll et al., 2007) describes collaboration approaches as providing a platform for different knowledge 
systems to be validated; explicitly considering the short- and long-term benefits for stakeholders; conducting research respectfully within research teams and with research participants; and placing emphasis on exploration, innovation and transformation. Collaboration recognises that learning and expertise are held by all stakeholders (Cram \& Pipi, 2000). Collaboration can also involve researchers going beyond their immediate responsibilities to the research. Researchers can contribute unforeseen benefits to the research collaboration; for example, skills transfers and capability building (Ahuriri-Driscoll et al., 2007). Descriptions of collaboration in kaupapa Māori research also include a commitment to continuously critique power effects through reflection and collaboration processes (Gifford \& Boulton, 2007).

According to Cram and Lenihan (2000), Kerr (2012) and Moewaka Barnes (2009), in utilising kaupapa Māori theory and research, KME can be described as seeking, exposing and highlighting the practised and lived realities of Māori using Māori forms of enquiry and accountability measures and criteria. KME can provide the evidence needed to assist an organisation, programme, project or initiative to find areas for improvement, or to generate an assessment of overall merit or worth (Davidson, 2005; Scriven, 2003). It is an evaluative practice that privileges processes rather than outcomes and determines merit and worth through a collective and collaborative process (Cram \& Lenihan, 2000; Jackson, 2000; Wells et al., 2008).

KME practitioners describe processes of exploration, innovation and explanation (Cram \& Lenihan, 2000; Kawakami, Aton, Cram, Lai, \& Porima, 2007) in pursuing information and knowledge formed through the lens of te ao Māori (Kerr, 2012). As a reflective and analytical process, KME is about determining the merit, worth and value of something against a collective Māori good; for instance, how a programme may align with the goal of self-determination (Kerr, 2012). Reflection has the potential to highlight strengths 
and the potential for change, and to assist in the development of pathways forward. More specifically, this can be done by making assessments and judgements within a Māori evaluative framework (Masters-Awatere, 2015).

KME shares its approach with empowerment evaluation because it recognises social problems and strives towards social justice through capacity building, mutual respect and accountability, community ownership and community knowledge. However, KME is specifically focused on the emancipation of Māori, striving towards self-determination, transformation and a space that is uniquely and unapologetically Māori. A KME approach does not have an entry and an exit point along the research journey; it is an ongoing relationship that can evolve and grow depending on the level of collaboration and partnership between the stakeholders and the evaluator (Cram \& Lenihan, 2000).

The interpretation and practice of kaupapa Māori vary across disciplines and contexts, and its methodologies are fundamentally complex, collectivist and evolving (Bevan-Brown, 1998; Levy, 2007; L. T. Smith, 2012; Te Awekotuku, 1991; Walker, 1996). Moreover, stakeholders and participants, as well as researchers, are all explicitly located within whānau, hapū and iwi realities (Walker, 1996). KME is a local performative endeavour rather than one where practitioners are looking for universalities. KME is context specific, always has historical significance, and is grounded in the politics, circumstances and economies of local people, focusing on movement within localised settings to confront and break through local systems of domination (Bishop, 2005).

Within the collaborative process and relationship envisioned with $\mathrm{KME}$, it is important to consider each stakeholder group's ecological, social, political and historical context. Māori and iwi organisations have their own unique and important contextual issues that need 
to be acknowledged during the collaborative journey. Cram (2005) notes that there are multiple dimensions to attend to.

1. Māori and iwi organisations may evolve a community-led response to an issue that needs urgent attention. Therefore, they may not begin with a grand plan for service provision, and this may have an impact on the structure and operations of the organisation as it evolves.

2. The services they provide are intrinsically connected and grounded in who they are as Māori.

3. They have dual accountabilities to both their funders and to the communities they are serving.

4. They are striving towards building their capacity and self-determination.

5. Political, historical, social, legal and economic factors impact on their organisation (Cram, 2005).

In spite of the strength and focus of the kaupapa Māori paradigm, the reality is that most KME is funded by Crown or NGO institutions that primarily exist in relations of domination over communities. Often Māori evaluators end up compromising on the practice of $\mathrm{KME}$, as funders determine parameters that do not necessarily align with an iwi's or hapū group's localised focus for KME (Stewart \& Swindells, 2003; Te Puni Kōkiri, 2000). There is thus a distinct disconnect between theory and practice for KME where it is consistently impinged upon by colonisation. As a result, practitioners argue that communities often lose out and evaluators are placed in conflicted positions (Kerr, 2012; Masters-Awatere, 2015).

Currently, there is limited literature on practical approaches to relationships, power and collaboration within kaupapa Māori contexts, and more specifically practices between Māori researchers and Māori and iwi organisations. Current guidelines and frameworks that focus on research with or involving Māori provide an overarching 
guide to a principled and ethical approach. The guidelines are framed for research involving Māori (Aotearoa New Zealand Evaluation Association (ANZEA) \& Social Policy Evaluation and Research Committee, 2008; Health Research Council of New Zealand, 2010), as opposed to providing guidance for Māori researchers (Cram, 2009; Moewaka Barnes, 2009). Although there is a considerable body of literature reporting on KME (Cram, 2005; Cram \& Lenihan, 2000; Masters-Awatere, 2015; Moewaka Barnes, 2009; Pihama, Cram, \& Walker, 2002b; Pipi et al., 2003; L. T. Smith \& Reid, 2000), peerreviewed publications about the experiences of Māori researchers collaborating with Māori and iwi organisations are scarce.

Guidelines and frameworks provide principles for practice and ethical guides. However, the interpretation and practical application of these principles can produce varying outcomes. Therefore, it is important to provide contextual examples of the utilisation of kaupapa Māori evaluation and detail what mutually beneficial relationships, power sharing and collaboration actually mean, the goals and written application of such agendas, and how these play out in the real world of KME. The current Health Research Council guidelines for researchers on health research involving Māori are an example of how guidelines can misinform process and approach for Māori (Health Research Council of New Zealand, 2010). They outline a consultative process rather than a processes of collaboration and partnership, focusing on a "culturally appropriate way" that is "responsive to Māori", rather than research that is grounded in mutually beneficial partnerships. Thus research is driven by those participating in or affected by the research — in terms of controlling the research agenda, methodology, development of findings and dissemination and control of the knowledge (Cavino, 2013). In KME the research power, focus and lens are shared with Māori, rather than Māori being consulted as a step along the research pathway, or as an afterthought. 
In this article we (the authors) seek to tell the story of what happened to the idealised scenario with which I (first author) approached the study. We will cover the twists and turns of a collaborative journey through an evaluation project, the conceptual and practical difficulties in applying KME to this exemplar, and the implications for KME research in the current policy climate.

\section{The project}

In 2009 a tripartite partnership between the National Health Medical Research Council (Australia), the Canadian Institutes of Health Research and the Health Research Council of New Zealand funded an international collaboration, named Strengthening Health Literacy among Indigenous People Living with Cardiovascular Disease, their Families, and Healthcare Providers, involving researchers in New Zealand, Australia and Canada. The broad aim of the New Zealand parent project, known as the Cardiovascular Disease (CVD) Medicines Health Literacy Intervention, was to determine if health literacy in relation to CVD medications could be strengthened through culturally appropriate interventions, targeting Māori patients and their whānau. Furthermore, it sought to establish whether such an intervention was associated with increased confidence and ability among Māori patients to self-manage their CVD, while at the same time empowering patients in interactions with health workers (Crengle, 2009). The project was run by two Māori health providers and Māori health researchers, who were all involved in the development of the research question, research methodology and funding application. The project team developed a pre/postintervention design with the two Māori health providers, one rural and one urban, drawing eligible participants from patients and whānau in their services (Crengle, 2009). The two Māori organisations involved were Te Hononga o Tāmaki me Hoturoa (Te 
Hononga), a kaupapa Māori non-government organisation located in South Auckland, and Ngāti Porou Hauora (NPH), a Māori primary health organisation that is now a charitable trust of Te Runanganui o Ngāti Porou. This iwi organisation provides health services to all in the Ngāti Porou rohe on the East Coast of the North Island.

In 2010 I was accepted to conduct a doctoral research project involving the qualitative aspects of the parent project. I was firstly introduced to the two Māori organisations at their research advisory group meetings. In meeting kanohi ki te kanohi (face-to-face), I sought consent from the parent research project to work with their research advisory groups (Ngāti Porou Hauora Charitable Trust, 2014). Once approved, I invited them to participate collaboratively in my project, including in methodological decisions, analysis, interpretation of data, and the concluding stages of the evaluation. I secured permission to attend their research advisory group meetings and obtained agreement that they would provide advice and feedback on aspects of my work.

The research advisory groups at Te Hononga and NPH included organisation and community members. They met at various stages of the parent project, providing input to project plans, and feedback and monitoring for both the research and evaluation projects. For $\mathrm{NPH}$ the research advisory group included a pakeke (Māori elder, providing cultural advice), an NPH board member (Māori) from the community in which the project was sited, the NPH research co-ordinator and 'local investigator' on the project team (Pākehā), a manager (Māori), a chronic care nurse (Māori), a general practitioner (Pākehā), and a kaiāwhina (community support worker) (Māori). All but one of these people who identified as Māori were from Ngāti Porou.

During the negotiation stage with Te Hononga, timeframe clashes for data collection meant that I could not include this service in my evaluation project's schedule, so after agreement with the research 
team I focused on working with NPH, with Te Hononga agreeing to key informant interviews. Organisational details such as a memorandum of understanding for the development of the KME were agreed to by me (Massey University), the project lead investigator (Auckland University) and the chief executive of NPH. Ethical approval was gained through the Massey University Human Ethics Committee (MUHECN 12/095).

\section{Ngāti Porou Hauora}

$\mathrm{NPH}$ was established as an incorporated society by iwi and community members in 1995 in response to the many issues faced by people in the region. These include poor health outcomes; limited access to health services; a determination to retain rural health services; a need to build a local Māori workforce; and a strong wish to develop innovative, locally relevant services that reflect Ngāti Poroutanga-health delivered in a holistic manner, consistent with the vision, values and strategic pou (goals) of Ngāti Porou (Te Runanganui o Ngāti Porou, 2012). The organisation has built a strong health delivery base over the past 21 years, with seven community healthcare clinics and a rural hospital. NPH is a primary health organisation and provides a range of personal health, public health and disability support services to all within the rohe. It has an enrolled population of approximately 8,854 , who reside in rural communities along the coast and in Gisborne city (Tan, 2016). The organisation is now governed by the Ngāti Porou Hauora Charitable Trust Board (Ngāti Porou Hauora, 2014).

$\mathrm{NPH}$ was involved from the expression of interest stage in developing the research proposal to the International Collaborative Indigenous Health Research Partnership for the research grant, and at each stage in the funding application process the research proposal was approved by the NPH board under the terms of its Research and Evaluation Policy (Ngāti Porou Hauora Charitable Trust, 2014). This policy 
requires projects to be of benefit to Ngāti Porou and to meet specific criteria, which include: contributing towards NPH strategic priorities for sustainable health gains and service development; use of culturally appropriate practices that align with Ngāti Porou tikanga; openness and transparency; strengthening strategic partnerships and resources; involving and/or developing Ngāti Porou and other Māori researchers; engaging whānau and hapū in planning, management and delivery where appropriate; and being approved by the relevant Research Ethics Committee (Ngāti Porou Hauora Charitable Trust, 2014).

\section{The kaupapa Māori evaluation}

The study aims were refined in negotiation with NPH and my supervisors. This included designing the evaluation in such a way that the needs of NPH, the parent project and the university institutional requirements for doctoral students could be met. Two broad aims were set:

- to carry out a KME of the effectiveness of the CVD Medicines Health Literacy Intervention: this aim involved conducting semi-structured interviews with patients and whānau, health professionals and Māori health literacy informants to gain insight into their perceptions, practices and experiences of the intervention

- to develop wider learnings in relation to health literacy interventions with Māori and Indigenous communities.

Here the plan was to work collaboratively with evaluation stakeholders in designing and testing a KME framework for health literacy interventions/services for NPH. Additional perspectives would come from interviews with local and international key informants on the topic of indigenous health literacy. These understandings would be synthesised and grounded through input and feedback from the NPH research advisory group. I aimed for a shared power-base, where hierarchy was 
limited and the research advisory group, staff and patients/whānau participants were invited to be a part of the decision-making process through hui, interviews, phone contact and email.

Invitations to participate were an important part of the collaborative process. The desire was for the methodological decisions, interpretation of data and final word to come from a collective voice, through a process where there would be a fair representation of the community, which honoured its diversity and open-ended communication, and where collaboration did not end at the end of a hui (meeting) but was an ongoing process. The kanohi ki te kanohi engagement was of paramount importance to the process, as it is understood within Poroutanga (Ngāti Porou identity) that to be heard you must be seen: he kanohi kitea. The value of being present_-showing your face in the community, helping, touching, gifting time and presence, where people can engage with your mauri (energy) and wairua (spirit) — is far more powerful than words on paper, an email communication or a phone call. In conventional evaluation this might be viewed as a conflict of interest, but my links with iwi and hapū enhanced the collaborative experience and complemented the principles and values of KME (L. T. Smith, 1999).

\section{He kanohi kitea}

Linda Smith (1999) identified he kanohi kitea - the face that is known and seen within a community. Cram (2010) adapts from Smith's work to incorporate he kanohi kitea as one of seven cultural values that guide Māori researcher practice. To be known in this research context is about more than being seen; it is about becoming intrinsically linked through whakapapa and service. To be known creates a foundation of trust and standing. As Rubin and Rubin (2012, p. 79) state, "trust increases as people see that you share a common background". I was born and raised in the commuity, I am 
invested and grounded in the community, and perceive the world through my Poroutanga, which is ordinary and everyday to me.

I grew up in Uawa and Tokomaru Bay and have used NPH services since I was in primary school. My whānau have been farmers on the East Coast for generations, and held manawhenua (territorial rights) before that. Many of my research participants knew my grandparents, and worked, played rugby and did business with them. My whakapapa, my people, my knowledge and connections were critical to my decision to join a research team guiding and implementing a project about health literacy in my takiwā. As a direct acknowledgement of my history with the region, I felt that relationships, power and collaboration were key terms of engagement because we were bound by whakapapa and everyday lived experiences through longstanding association.

All the evaluation participants were recruited by NPH based on the parent project criteria, and, as it turned out, I had connections to six out of the nine participants. Since my involvement in the project in 2011 my whānau have made it a priority to attend marae (meeting grounds) and community events on my behalf because I live in Auckland. This was never a request made on my behalf, but rather a right and responsibility taken on by my whānau. My aunt, uncle and cousins joined the parent project hui when they were held at Hinerupe Marae; they worked in the kitchen and provided blankets and bedding to the international guests.

\section{Collaboration envisaged}

Collaboration between me and the research advisory group meant involvement with NPH at all stages of the evaluation: from the development of the KME framework, communication processes, data collection methods, recruitment of participants, to the development of the evaluation criteria with research stakeholders. Structurally 
the KME design was shaped by the relationship between the parent project and NPH. Due to university institutional NPH board requirements and parent project data collection timeframes, I was obliged to conduct patient and staff interviews as the collaborative design of the KME framework was developing. I also followed the NPH board policy by using local te reo me ngā tikanga Māori (Māori philosophy, knowledge, practice and identity) practices (Ngāti Porou Hauora, 2014).

During the development of the KME framework, the research advisory group met with me at the NPH offices in Te Puia Springs to plan, outline, develop and refine the KME framework. Four hui (gatherings), which were separate to the parent project hui, were held for planning, implementation, analysis and in the concluding stages of the evaluation. Partnership (active collaboration) and participation (deliberative engagement) were imperative to ensure that the information generated from the evaluation was context focused. The first hui introduced the evaluation in terms of its placement with regard to the parent project and intervention, as well as the proposed processes. The second hui involved identifying visions and goals for the community with regard to health and how the health literacy intervention trial aligned with these aspirations, as well as developing the evaluative criteria, and defining indicators for what would make an effective intervention. A third hui refined the evaluation framework and outlined data collection plans, backed by literature on current evaluation models and frameworks used in kaupapa Māori health contexts. The fourth hui provided feedback on the draft theme development and findings from analysis of the interviews with patients and health professionals to further refine the evaluation criteria and framework. A final hui will disseminate all aspects of the KME, including framework, data analysis and findings, and will seek research advisory group feedback on the project overall. 
Data from the research advisory group hui were collected through mp3 recordings of hui, transcribed verbatim and supplemented with email correspondence. Additional information, including post-it notes from working sessions, framework drafts and researcher field notes, were included in the data set.

\section{Titiro, whakarongo ... kōrero}

Another aspect of kaupapa Māori I utilised was the concept 'Titiro, whakarongo ... kōrero'. L. T. Smith (1999, p. 120) and Cram (2010, p. 9) describe this as an imperative to the researcher to "look and listen (and then maybe speak), and to develop understanding to find a place from which to speak". In essence, this was my reference for engagement during the research process. I only spoke with approval and by invitation, and regarded my evaluative position as a facilitative role, a co-creator of understanding. I wanted the research advisory group to build enthusiasm, ownership, commitment and a sense of purpose to enable the intervention to be evaluated on their terms, with their criteria and against their indicators of effectiveness.

When it was time to facilitate the second research advisory group meeting, I felt that I had stepped out on a star. This star aimed to take the research advisory group on a journey of exploration and connection to the values and principles that guided their practice. The hui was about building confidence within a process of KME, thereby allowing everyone to work confidently within the complexities of understanding. The intention of the hui was to understand and capture the participants' collective values and principles, then use them to guide the evaluation criteria.

When the meeting commenced I provided a draft framework to the research advisory group asking for input and feedback on my interpretation of the work that was conducted that day. This was done through email communication, as organisational and parent 
project time reduced contact time. I received two email responses. The first highlighted a spelling mistake in the framework and the second congratulated me on my doctoral enrolment and encouraged me to "come home with the tohu [qualification]". I was left with a feeling of uncertainty. I was unsure how to process the silence on the context, as there was no rejection of the information but also no written acceptance. I questioned my approach and reflected on the timeframe restrictions and what the lack of content feedback might mean to the evaluation. I was in between three entities to which I had accountabilities: the university, where my PhD was based, NPH, and the parent project. All needed their accountabilities to be met and timeframes to be adhered to. I questioned whether I had compromised the KME aims for external party agendas, but I felt I needed to carry on and continued to work to meet the evaluation needs.

Six months later I completed data collection with patients and health professionals. I refined the framework in light of the participant themes and presented the framework back to the research advisory group at our third hui. Due to time constraints I was unable to receive feedback kanohi ki te kanohi from the research advisory group and was informed that members would email. Feedback was not forthcoming, even after prompting from the research co-ordinator. For me, the non-response was again difficult to process because I took it as a sign that the research and the process were not relevant or effective. I wanted to honour a kaupapa Māori process that went beyond notions of being 'responsive' and conducting research in a 'culturally appropriate' manner and move instead towards notions of shared input and benefit. I felt I had missed the mark. For me, input meant voice, and I was met with silence. I questioned whether I was honouring the participants' ontological positions (lived realities and expressions) when it was only my interpretations that were being recorded. 
This reflective process was important to me, as I wanted to be able to question the process while it was happening, and not assume and overstate my position as an iwi member or a Māori researcher. Cram et al. (2006) reflected on this dilemma, acknowledging that although Māori research capacity is growing, "the guidance offered to researchers does not fully explore the issues faced by Màori researchers who are conducting research with Māori” (p. 47). This was my reality as I negotiated, contemplated and questioned myself, particularly considering the complex ways I was both insider to the research and an outsider, with responsibilities and consequences on both sides. The less-than-anticipated level of engagement with the process was, I reflected, possibly in part due to competing claims on the advisory group members and their interests and skills in areas other than health literacy. If so, I needed to shift my expectations and assumptions.

\section{Contextual understanding}

Initially I had envisaged my work with the research advisory group would involve their participation from a position of understanding the content and context of the CVD Medicines Health Literacy Intervention. I assumed members would have knowledge of the concept of health literacy and what it meant within the context of the project and the community, based on their involvement with the intervention project.

At the time the group was set up, however, health literacy was seen as a relatively new approach. The existing members of the advisory group were people with considerable local knowledge and understanding. I learned that ideas about health literacy varied across the group, and that they frequently differed significantly from the concept the research team was working with, in terms of health literacy being defined as the degree to which individuals have the capacity to 
obtain, process and understand the basic health information and services needed to make appropriate health decisions (Kickbusch, Wait, $\&$ Maag, 2005). As identified in the parent project article (Lambert et al., 2014), health literacy is an evolving concept, and interpretations and understanding can be diverse. However, limited understanding of health literacy has consequencies in terms of addressing the health literacy barriers that patients face.

The following excerpt is from the first research advisory group meeting with me (Interviewer), held for the purpose of developing an evaluation framework for future use.

Interviewer: What does health literacy mean to you and your mahi?

Participant A: I'm not really sure. It's about the words, literacy. I think it's about promoting health messages, like our posters that we have. There's one over there [pointing to the wall]. It's literacy, messages, pamphlets.

Participant B: It's about, how I can sit there and Doc can talk and I understand. When we talk at lunch time, I sort of know what he talks about now.

Participant C: It's also about prevention, getting the target group of 35-about-50 - we [are] trying to focus on that target group. And I'm always going 'prevention, prevention'. Let's prevent you from a heart attack, let's prevent you from having to go on pills.

Participant A expresses uncertainty about the meaning of health literacy, and while Participant B expresses some of the main ideas, they appear to relate rather generally to her work rather than being seen as something that patients use to understand and control their personal circumstances. Participant $\mathrm{C}$ speaks about the health promotion agenda of prevention in terms of CVD and medications, the two key focus areas of the parent project. While health literacy may have a legitimate goal of prevention through patient use of knowledge 
to ensure the correct use of medications and proper application of other treatments, Participant $\mathrm{C}$ constructs it as the main focus of health literacy.

This discussion was significant because it enabled the research advisory group to talk about their explanations of health literacy and understanding of the intervention. Realising the diversity of meanings ascribed to health literacy clarified and changed the possibilities for what could be achieved via the participatory process I was pursuing. It reinforced the need to gain - and not assume-an understanding of the research advisory group members' contexts, views and understanding of health literacy interventions and, in this instance, their knowledge of the specifics of the project.

\section{Participant priorities}

\section{Masters-Awatere states that}

to be effective in evaluations we must take seriously an ethic of cultural safety that acknowledges the unique and collective needs of each community, engages in evaluation relationships with each of the stakeholder groups, and interrogates power and privilege. (Masters-Awatere, 2015, p. 246)

During the first two hui it emerged that for some members of the group it was challenging to focus on health literacy concepts, when for them the more immediate needs were a priority within the community. In the following excerpt participants were asked to write NPH health goals and broader community health aspirations for hauora (health) on Post-it notes. The notes were then assembled on a whiteboard in a poster format, and similar ideas grouped together to form themes. The following excerpt is before we began writing on the Post-it notes

Interviewer: What other health goals do we have when it comes to thinking about hauora? 
Participant A: It's hard to think about good health for our people when we don't even have the basics. See up the coast water is a big factor, access to clean water in summer is hard, it's expensive, so trying to implement things like eating healthy kai, when they don't even have clean water, it's a hard one.

Interviewer: So would it be fair to add clean water to one of our goals? Participant A: Yeah, it's hard to move past. It's like kaitiakitanga [guardianship], all our responsibility.

Participant B: Tino rangatiratanga [sovereignty] that's an important one. It needs to come back to that ...

Participant C: We need to improve on the way we do our contracts so that we can streamline our focuses.

Participant E: Yeah, like getting more ongoing funding 'cause we can put all this effort in and then six months later we can't offer the same services [writing on Post-its and placing on board].

Participant C: Would be better to build up more focus on prevention, have more of a positive move.

As the research advisory group hui progressed I needed to consider how the parent project research focus might differ from the more immediate concerns of the group members and their perceptions of the needs of the community. By staying open to issues that might arise in the research advisory group rather than focusing on conventional understanding of health literacy, I gained fresh insight into the wider challenges facing those concerned with health in these communities. This 'brainstorming' data demonstrates both their understanding of what could improve the health of their communities and describes the challenges faced by the parent project. As Participant A reflects, "It's hard to think about good health for our people when we don't even have the basics". 
It may be that health literacy for over 50 s is useful, but the health of the community is jointly constructed as being about fundamentals such as clean water, self-determination and stable funding arrangements, among other things. Participant C's reiteration of the call for preventive and positive approaches is an example of the complexity of needs that exist in the community. This example provides context for the diverse responses and challenges presented in the research advisory group data.

\section{Reflections}

KME is about seeking a relational status with our communities in the search for understanding and knowledge (L. T. Smith, 1999), as a basis for understanding the impact of an intervention in a community. All research stakeholders, including health consumers and community members, are seen as legitimate co-producers of knowledge in ways that are not traditionally approached by Western models of evaluation (Ritchie, 2002). As an iwi member I feel obligated to my people and responsible for the kōrero they have shared with me, and it is my responsibility to prioritise their voice in this research because they will be directly affected by the outcomes.

KME was the platform for an idealised scenario of collaboration, where I was the facilitator of the process, welcoming the adjustment of parameters by participants while making sure the invitation to share a pathway forward was available, accessible and achievable. Ultimately, KME was about aspirations of co-ownership, mutually beneficial outcomes and shared power, through prioritising the participants' voices to shape and develop the criteria to determine the effectiveness of the intervention. Stakeholders' understanding of health literacy and the intervention were varied, however, making the vision of collaboration more complex as individuals worked through personal, community and organisational implications. 
During this collaborative journey I have learnt that being adaptive and responsive is an important part of KME by making sure that we, as researchers, are consistently checking that we are on the right track, that we have heard right and, if this is the case, that our pathway forward is essential. The collaborative process has highlighted the importance of being heard and being able to listen, as it is written in an old whakataukī (proverb): "Whakarongo, whakarongo, whakarongo" (Listen with your upoko [head], manawa [heart] and puku [stomach]). It is understood that in te ao Māori it takes more than ears to listen: we listen with our heads to make logical sense of what we hear, against our experiences and understanding of the world. We hear with our hearts, the emotional connection to what resonates with us. Lastly, we hear with our puku, listening to our intuition, our foresight. If we can provide environments and spaces where listening on all levels can take place, we can start building our knowledge capacities and our collaborative endeavours.

There is still an undercurrent of colonial power that we have to mindfully and actively resist in creating collaborative approaches. Communities are still fighting for fundamentals such as clean water, self-determination and stable funding arrangements. Māori organisations are continuously balancing the tensions between community need and funding requirements, while KME approaches are trying to create spaces for understanding lived realities, and practical processes that avoid added pressure on communities yet produce timely outcomes.

At times the KME process was challenging, as the research design and implementation conformed to external time frames and resources due to administration pressures. This restricted the time and contact available to develop collaborative approaches, potentially undermining the principles and values that KME is founded on. On reflection I gained many insights into the KME process, learning that 
KME assumes certain levels of power on the part of the researcher (Carlson, Moewaka Barnes, Reid, \& McCreanor, 2016; Moewaka Barnes, 2006). This reality sits in opposition to the notion of equality that dominates the literature. As a student working with more senior researchers, and as a younger person working with the research advisory group, my experience further affirmed this tension. Due to the nature of the research, I was on my own at times, and so collaborative approaches did not conform to the assumed power imbalance between the researcher and the researched, and also in relation to the roles that parties played. Having a senior Māori academic as my chief $\mathrm{PhD}$ supervisor provided me with support, guidance and clarity, and enabled me to reflect on my experiences and move forward.

As described in this article, I actively sought opportunities for input, spent considerable time on this aspect of the evaluation and continued to seek input despite experiencing concerns when little feedback was received. Relatively low levels of input from the advisory group led me to assume that the relationship was no longer collaborative. During discussions with my supervisor, however, she caused me to rethink this assumption. We questioned the nature of collaboration: in particular, whether it meant equal input, or whether collaboration was still occurring when input differed but power was shared and engagement opportunities were always offered and pursued. I came to think that it is not about power sharing, but power acknowledgement and shift: I had certain powers and other stakeholders had power. In practice I needed to do the bulk of the work consequently, collaboration was not about requiring considerable input, but about keeping communication open and offering opportunities for engagement that other parties (research advisory group) could then make choices about. While input may not have been equal, I hoped it was equitable. 


\section{Concluding remarks}

Through this KME experience I have come to understand the complexity of grounding my approach in kaupapa Māori practices, as I was consistently reminded at every decision point and movement that we work within a colonial system that perpetuates Western thinking and practice, even in our small, vulnerable Māori spaces. While I chose to be a part of a larger project because I wanted to gain maximum impact for my community, I recognise that a $\mathrm{PhD}$ can be an individualistic pursuit of knowledge but wanted to be in a position to be a part of something that could change people's lives at the outset, that gave voice to those most affected, and that provided me with the opportunity to work with brilliant minds and learn from my elders. I chose to see this process as transformative, not in an earthshattering way but in a way that is valiant in its pursuit of making a contribution to the area of KME. Moving forward, a key learning has been the unexpected power inequalities within KME, and I would like to be able to consider and spend more time unpacking these dynamics.

\section{Acknowledgements}

My sincere gratitude to our kaumātua (elders), who have provided me with rich experiences, for the conversations, wisdom and the continual encouragement. I would like to thank the community participants who have provided insight into and grounding for the research. I would like to thank Ngāti Porou Hauora staff for your time and guidance. I also acknowledge the support and encouragement from the Māori and Indigenous doctoral programme (MAI) and Whāriki Research Rōpū.

This research was funded by the Health Research Council, Ngā Pae o te Māramatanga, Māori Education Trust, Massey University and the Ministry of Health. The qualitative evaluative aspects of the research were originally advertised by and funded from the 
International Collaborative Indigenous Health Literacy Partnership Grant project known as the Cardiovascular Disease (CVD) and Medicines Intervention. This funding was not utilised for this research as I was awarded a University of Auckland Doctoral Scholarship and thereafter a Health Research Māori Doctoral Scholarship.

\section{About the authors}

Teah Carlson is of Te Whānau a Apanui and Ngāti Porou descent. She is a PhD scholar at Whāriki Research Centre, Massey University. She has experience in qualitative methods, strategy and evaluation, especially involving working with Mãori communities where collaboration, partnership and participatory community action were key to the research development, process and outcomes. Her strengths are in kaupapa Mãori research, evaluation and action research. This research is a part of her $\mathrm{PhD}$ in public health, which is a Health Research Council-funded project entitled Indigenous Health Literacy Framework: Evaluation of a Health Literacy Cardiovascular Disease Intervention.

T.A.Carlson@massey.ac.nz

Professor Helen Moewaka Barnes is of Ngāti Wai, Ngāti Hine and Ngāti Manu descent. She is the Director of Whāriki and Co-director of the SHORE and Whāriki Research Centre. She has worked on research in many areas, more recently involving relationships between the health of people and the health of environments, sexual coercion, alcohol, and youth well-being and identity. Her work is both qualitative and quantitative, and she is also involved in developing research within Māori paradigms.

h.moewakabarnes@massey.ac.nz 
Associate Professor Tim McCreanor is a senior social scientist at SHORE and Whāriki Research Centre, Massey University, in Auckland, Aotearoa New Zealand. He has particular experience in qualitative approaches and his work focuses on social change projects relating to indigenous rights, population health and decolonisation. T.N.McCreanor@massey.ac.nz

\section{References}

Ahuriri-Driscoll, A., Hudson, M., Foote, J., Hepi, M., Rogers-Koroheke, M., Taimoana, H., et al. (2007). Scientific collaborative research with Maori communities: Kaupapa or kupapa Maori? AlterNative: An International Journal of Indigenous Peoples, 3(2), 61-81.

Aotearoa New Zealand Evaluation Association (ANZEA) \& Social Policy Evaluation and Research Committee. (2008). SPEaR good practice guidelines. Wellington: Author.

Bevan-Brown, J. (1998). By Māori, for Māori, about Māori—is that enough?

In T. P. Hauora (Ed.), Te oru rangahau: Mãori research \& development conference proceedings (pp. 231-249). Palmerston North: Te Pūtahi-ā-Toi.

Bishop, R. (1996). Collaborative research stories: Whakawhänaungatanga. Palmerston North: Dunmore Press.

Bishop, R. (1999). Kaupapa Maori research: An indigenous approach to creating knowledge. In N. Robertson (Ed.), Maori and psychology: Research and practice. Hamilton: Maori and Psychology Unit.

Bishop, R. (2005). Freeing ourselves from neo-colonial domination in research: A Maori approach to creating knowledge. In N. K. Denzin \& Y. S. Lincoln (Eds.), The Sage handbook of quality research (pp. 109-138). Thousand Oaks, CA: Sage Publications.

Bishop, R., \& Glynn, T. (1999). Achieving cultural integrity within education in Aotearoa/New Zealand. In K. Cushner (Ed.), Intercultural perspectives on intercultural education. New York, NY: Lawrence Erlbaum Associates. 
Carlson, T., Moewaka Barnes, H., Reid, S., \& McCreanor, T. (2016). Whanaungatanga: A space to be ourselves. Journal of Indigenous Wellbeing, 1(2), 44-59.

Cavino, H. M. (2013). Across the colonial divide: Conversations about evaluation in indigenous context. American Journal of Evaluation, 34(3), 339-355.

Cochran, P. A. L., Marshall, C. A., Garcia-Downing, C., Kendall, E., Cook, D., McCubbin, L., et al. (2008). Indigenous ways of knowing: Implications for participatory research and community. American Journal of Public Health, 98(1), 22-27. Retrieved from http://doi.org/10.2105/ AJPH.2006.093641

Connelly, F. M., \& Clandinin, D. J. (1990). Stories of experience and narrative inquiry. Educational Researcher, 19(5), 2-4.

Cram, F. (2005). An ode to Pink Floyd. Chasing the Magic of Maori and Iwi Providers, 1, 1-13.

Cram, F. (2009). Maintaining indigenous voices. In D. Mertens \& P. Ginsberg (Eds.), The handbook of social research ethics (pp. 308-322). Los Angeles, CA: Sage.

Cram, F. (2010). Appreciative inquiry. MAI Review, 3, 1-13.

Cram, F. (2015). Lessons on decolonizing evaluation from kaupapa Māori evaluation. Canadian Journal of Program Evaluation, 30(3), 296-312.

Cram, F. (2016). Lessons on decolonizing evaluation from kaupapa Maori evaluation. Canadian Journal of Program Evaluation, 30(3), 296-312.

Cram, F., \& Lenihan, T. (2000). Kaupapa Maori principles, procedures and pratices. Auckland: International Reseach Institute for Maori and Indigenous Education.

Cram, F., McCreanor, T., Smith, L., Nairn, R., \& Johnstone, W. (2006). Kaupapa Māori research and Pākehā social science: Epistemological tensions in a study of Māori health. Hülili, Multidiciplinary Research on Hawaiian Well-Being, 3(1), 41-68. 
Cram, F., \& Pipi, K. (2000). Mãori research development: Vol. 1: Mãori provider success. Wellington: Te Puni Kōkiri.

Crengle, S. (2009). International collaborative indigenous health research partnership grant. Auckland: University of Auckland.

Davidson, E. J. (2005). Evaluation methodology basics: The nuts and bolts of sound evaluation. Thousand Oaks, CA: Sage Publications.

Eketone, A. (2008). Theoretical underpinnings of kaupapa Maori directed practice. MAI Review, 1, 12-19.

Gifford, H., \& Boulton, A. (2007). Conducting excellent research with indigenous communities: Balancing commitment to community and career. AlterNative: An International Journal of Indigenous Peoples, 3(2), $24-45$.

Health Research Council of New Zealand. (2010). Guidelines for researchers on health research involving Mãori. Auckland: Author.

Jackson, M. (2000). Maori health research and Te Tiriti o Waitangi. Wellington: Author.

Kawakami, A., Aton, K., Cram, F., Lai, M., \& Porima, L. (2007). Improving the practice of evaluation through indigenous values and methods: Decolonising evaluation practice-Returning the gaze from Hawai' $i$ and Aotearoa. Hulili: Multidiciplinary Research on Hawaiian Well-Being, 4(1).

Kerr, S. (2011). Kaupapa Māori theory-based evaluation. Kārearea-Maori and Indigenous Evaluation, 1(1) 8.

Kerr, S. (2012). Kaupapa Maori theory based evaluation. Evaluation Journal of Australasia, 12(1), 6-18.

Kerr, S., Penney, L., Moewaka Barnes, H., \& McCreanor, T. (2010). Kaupapa Māori action research to improve heart disease services in Aotearoa, New Zealand. Ethnicity \& Health, 15(1), 15-31.

Kickbusch, I., Wait, S., \& Maag, D. (2005). Navigating health: The role of health literacy. London, UK: Alliance for Health and the Future, International Longevity Centre. 
Lambert, M., Luke, J., Downey, B., Crengle, S., Kelaher, M., Reid, S., et al. (2014). Health literacy: Health professionals' understandings and their perceptions of barriers that indigenous patients encounter. BMC Health Services Research, 14(1), 614-624.

Levy, M. (2007). Indigenous psychology in Aotearoa: Realising Mãori potential. Hamilton: University of Waikato.

Masters-Awatere, B. (2015). "That's the price we pay": Kaupapa Mãori programme stakeholder experiences of external evaluation. Hamilton: University of Waikato.

Moewaka Barnes, H. (2000). Kaupapa Maori: Explaining the ordinary. Pacific Health Dialog, 7, 13-16. Retrieved from http://www.ncbi.nlm.nih. gov/pubmed/11709875

Moewaka Barnes, H. (2003). Maori and evaluation: Some issues to consider. In N. Lunt, C. Davidson, \& K. McKegg (Eds.), Evaluating policy and practice: A New Zealand reader (pp. 146-150). Auckland: Pearson Education New Zealand.

Moewaka Barnes, H. (2006). Transforming science: How our structures limit innovation. Social Policy Journal of New Zealand, 29, 1-16.

Moewaka Barnes, H. (2009). The evaluation hikoi: A Maori overview of programme evaluation. Auckland, Massey University.

Ngāti Porou Hauora. (2014). Ngāti Porou Hauora strategic plan 2014-2018. Gisborne: Author.

Ngāti Porou Hauora Charitable Trust. (2014). Health research \& evaluation stakeholder policy. Gisborne: Author.

Noddings, N. (1995). Philosophy of education. Boulder, CO: Westview Press.

Nutbeam, D. (2008). The evolving concept of health literacy. Social Science \& Medicine, 67(12), 2072-2078.

Pihama, L., Cram, F., \& Walker, S. (2002a). Creating methodological space: A literature review of kaupapa Maori research. Canadian Journal of Native Education, 26, 30-43. 
Pihama, L., Cram, F., \& Walker, S. (2002b). Kaupapa Maori principles and practices: A literature review. Wellington, Te Rōpū Rangahau Hauora a Eru Pōmare \& Te Puni Kōkiri.

Pipi, K., Cram, F., Hawke, R., Hawke, S., Huriwai, T. M., Keefe, V., et al. (2003). Mãori and iwi provider success: A Research report of interviews with successful iwi and Mãori providers and government agencies. Wellington, Te Puni Kokiri.

Ritchie, J. (2002). "It's becoming part of their knowing": A study of bicultural development in an early childhood teacher education setting in Aotearoa/New Zealand. Hamilton: University of Waikato.

Rubin, H. J., \& Rubin, I. S. (2012). Qualitative interviewing: The art of hearing data (3rd ed.). Thousand Oaks, CA: Sage Publications.

Scriven, M. (2003). Evaluation theory and metatheory. In T. Kellaghan, D. L. Stufflebeam, \& L. A. Wingate (Eds.), International handbook of educational evaluation: Vol. 1 (pp. 15-30). Dordrecht, The Netherlands: Kluwer Academic Publishers.

Smith, G. H. (1997). The development of kaupapa Mäori: Theory and praxis. Auckland: University of Auckland.

Smith, L. T. (1999). Decolonising methodologies: Research and indigenous peoples. London, UK: Zed Books and University of Otago Press.

Smith, L. T. (2012). Decolonizing methodologies (2nd ed.). Dunedin: Otago University Press.

Smith, L. T., \& Reid, P. (2000). Maori research development: Kaupapa Maori principles and practices. Wellington: Te Puni Kokiri.

Stewart, B. J., \& Swindells, J. (2003). “Setting up for sucess”: evalution and development-helping service providers do better. In L. C. Davidson \& K. McKegg (Eds.), Evaluating policy and practice: A New Zealand reader (pp. 157-162). Auckland: Pearson Education New Zealand.

Tan, L. (2016). Ngati Porou health dashboard. Gisborne: Ngati Porou Hauora.

Te Awekotuku, N. (1991). He tikanga whakaaro research ethics in the Maori community. Wellington: Manatu Māori. 
Te Puni Kōkiri. (2000). Mãori provider views of government funding. Wellington: Author.

Te Runanganui o Ngāti Porou. (2012). Tai ora strategic response and action plan optimising the performance of Ngäti Porou Hauora. Gisborne: Author.

Walker, S. (1996). Kia tau te rangimarie: Kaupapa Mãori theory as a resistance against the construction of Mãori as the other. Auckland: University of Auckland.

Wells, S., Furness, S., Rafter, N., Horn, E., Whittaker, R., Stewart, A., et al. (2008). Integrated electronic decision support increases cardiovascular disease risk assessment four fold in routine primary care practice. European Journal of Cardiovascular Prevention \& Rehabilitation, 15(2), 173-178. 